\title{
PERENCANAAN STRATEGIS SISTEM INFORMASI (STUDI KASUS PDAM JAYA)
}

\author{
Muhammad Firdaus \\ Teknik Informatika, Universitas Indraprasta PGRI Jakarta \\ Email: dasurichi@gmail.com
}

\begin{abstract}
Abstrak
Perkembangan teknologi informasi dan komunikasi yang semakin pesat, memungkinkan pihak menajemen perusahaan dapat mengoptimalkan kualitas pelayanan yang lebih baik. Berdasarkan hasil studi di perusahaan PDAM JAYA (Perusahaan Daerah Air Minum JAkarta RaYA), proses pengiriman laporan rekapitulasi pelanggan yang tidak tertata dengan baik menjadikan suatu masalah tersendiri, yang timbul karena kurang memadainya fasilitas infrastruktur TI (Teknologi Informasi). Perencanaan strategis Sistem Informasi digunakan untuk menunjang fungsi dan peranan perusahaan tersebut secara optimal dalam melakukan monitoring dan controlling terhadap kedua Mitra Swasta. Metodologi yang digunakan akan merapkan beberapa fase tahapan dari kerangka kerja Tozer, sedangkan beberapa metode analisis lainnya yang digunakan untuk mendukung penelitian ini, diantaranya adalah: SWOT (Strengths, Weaknesses, Opportunities, and Threats),Critical Success Factors (CSFs), McFarlan'sApplicationPortfolio, Value Chain, dan PEST (Politik, Ekonomi, Sosial, dan Teknologi). Hasil dari penelitian ini akan didapat solusi stratejik Sistem / Teknologi Informasi yang disertai dengan dukungan teknis atas infrastruktur TI yang sesuai untuk diterapkan di perusahaan tersebut, sehingga tepat guna dan selaras dengan kebutuhan bisnis perusahaan di masa depan, dan dapat menata kembali arsitektur teknologi informasi, dengan menambah sejumlah perangkat pendukung lainnya agar dapat mengantisipasi peningkatan pengelolaan kapasitas data-data online Mitra Swasta.
\end{abstract}

Kata Kunci: Perusahaan, Mitra Swasta, Metodologi, Sistem Informasi, Teknologi Informasi

\begin{abstract}
Rapid development of information technology and communication allows company management to better optimize their service quality. Based on the result of study in PDAM JAYA (Perusahaan Daerah Air Minum JAkarta RaYA), the delivery of improperly prepared customers' summary reports is an particular issueraising due to inadequate IT facilities. Strategic Planning for Information System is used to optimally support the function and role of the company in monitoring and controlling two Private Partners. Methodology used will apply some steps from Tozer framework, while some other analysis methods used to support this research are : SWOT (Strengths, Weaknesses, Opportunities, and Threats), Critical Success Factors (CSFs), McFarlan's Application Portfolio, Value Chain, dan PEST (Political, Economic, Socialand Technological). The result of this research will provide an Information System / Technology strategic solution with technical supportsfor IT facilities suitable to use by the company so that the companycan efficientlyfulfill its needs in the future and rearrange the information technology architecture by adding a number of other supporting facilitiesin order to anticipate the increase of online data capacity management in Private Partner.
\end{abstract}

Keywords:Company, Private Partners, Methodology, Information System, Information Technology

\section{Pendahuluan}

Bergabungnya dua Mitra Swasta, yaitu: PT. Palyja dan PT. Thames sebagai rekan kerja utama yang berperan dalam mendukung penyediaan dan pengelolaankegiatan operasional yang berkaitan dengan masalah tagihan pelanggan, penyediaan infrastruktur pipa penyaluran air, dan instalasinya. Hal tersebut memungkinkan adanya sistem monitoring yang dapat 
mengawasi jalannya pelaksanaan kegiatan tersebut. Walaupun kini perusahaan daerah tersebut, sekarang tidak lagi berperan aktif secara langsung atas masalah yang berkaitan dengan aktifitas kegiatan operasional. Tetapi dalam memberikan keputusan dan kebijakan dalam mengendalikan laju operasional yang akan dihadapi, baik itu berhubungan dengan mutu kualitas pelayanan, peran Perusahaan sangat dibutuhkan.

McFarlan (di dalam Lederer dan Sethi, 1988:445) berpendapat bahwa, penerapan perencanaan stratejik Sistem Informasidi perusahaan dapat membantu mengidentifikasi target yang paling sesuai dalam mengotomasi dan menjadwalkan palaksanaan proyek proyek sistem dan teknologi informasi di waktu yang akan datang,sehingga dari pernyataan tersebut dapat dibuat pertanyaan penelitian, yaitu: "bagaimana rumusan perencanaan stratejik SI (Sistem Informasi) /TI (Teknologi Informasi) pada perusahaan dalam mendukung fungsi organisasi pasca perjanjian kerjasama dengan Mitra Swasta?".

Beberapa permasalahan yang seringkali dihadapi oleh pihak manajemen Perusahaan dalam menjalankan fungsi dan peranannya sehari-hari,diantaranya:

1. Proses pengiriman data-data laporan rekapitulasi pelanggan oleh Mitra Swasta tidak tertata dengan baik.

2. Tidak terintegrasinya Sistem Informasi diantara kedua belah pihak.

3. Kurang memadainya fasilitas infrastruktur TI (Teknologi Informasi)yang dimiliki oleh Perusahaan.

Sedangkan yang menjadi batasan masalahdari penelitian ini adalah bahwa dalam mengidentifikasi kebutuhan TI (Teknologi Informasi) hanya mencakup pendayagunaan yang dilakukan di internal maupun eksternal organisasi, pengkajian masalah hanya berkaitan dengan fungsi dan peranan Perusahaan dalam menjalankan aktifitas kegiatan setiap harinya, serta merencanakan solusi dan membuat deliverable yang tepat untuk diterapkan di perusahaan. Namun demikian, tidak akan membahas perancangan Sistem Informasi dan halhal rinci yang terkait dengan lingkup masalah diluar konteks penelitian ini.

Tujuan dari penelitian ini, dimana dapat memberikan analisa yang jelas atas penerapan dan pemanfaatan teknologi informasi sesuai dengan pendekatan best practice yang telah ada, serta memberikan acuan kepada perusahaan atas kajian analisis dari penelitian ini. Sedangkan manfaat yang bisa dipetik dari hasil penelitian ini diharapkan dapat memberikan solusi optimal sebagai bahan masukkan dan tanggapan yang bersifat membangun. Walaupun hal itu berupa suggestion dan recommendation.

\section{Tinjauan Pustaka}

\section{Definisi Perencanaan Strategis Sistem Informasi}

Konsep perencanaan strategis Sistem Informasidilihat dari sudut pandang yang berbeda-beda dari beberapa para ahli, seperti penuturan dari Mclean dan Soden (di dalam Lederer dan Sethi, 1988:445-446) yang mengungkapkan bahwa perencanaan strategis Sistem Informasi bertujuan untuk memperkirakan sumber daya TI (Teknologi Informasi) yang paling tepat dibutuhkan untuk menentukan peluang yang lebih besar dalam meningkatkan kinerja departemen SIM (Sistem Informasi Manajemen) agar lebih baik lagi. Sedangkan menurut Lederer dan Sethi (1988:446), bahwa perencanaan strategis Sistem Informasi merupakan proses identifikasi portofolio aplikasi yang dapat membantu mengeksekusi atau mengeksploitasi perencanaan bisnis organisasi. Sependapat dengan pernyataan di atas, menurut Boynton dan Zmud (1987:59), bahwa perencanaan stratejik Sistem Informasi digambarkan sebagai aktivitas organisasional yang diarahkan untuk :1) mengenali peluang secara organisasi dalam mempergunakan TI, 2) menentukan kebutuhan sumber daya dalam memanfaatkan peluang, dan 3) mengembangkan rencana strategis dan tindakan untuk menyadari peluang yang ada dan memenuhi keperluan sumber daya.Secaragaris besar Brumec dan Vrcek (2004) juga mendefinisikan perencanaan strategis Sistem Informasi tidak 
hanya dipandang sebagai suatu perencanaan jangka panjang yang efektif dalam menerapkan SI (Sistem Informasi) / TI (Teknologi Informasi), tetapi juga harus selaras dengan perencanaan stratejik keseluruhan bisnis organisasi. Dari keempat pernyataan tersebut dapat diambil kesimpulan bahwa suatu perencanaan stratejik Sistem Informasi diperuntukkan untuk bisa selaras dengan strategi bisnis organisasi.

\section{Penentuan Kerangka Kerja PSSI}

Kerangka kerja yang akan digunakan oleh penulis adalah model kerangka kerja dari Tozer, dimana kriteria-kriteria pendukung tersebut dapat memberikan pandangan yang positif bagi manajer puncak (top management) terhadap pengembangan sistem dan teknologi informasi yang berdaya guna tinggi dengan memberikan nilai tambah di setiap penerapannya, sehingga menghasilkan nilai komoditas yang lebih besar dan bermanfaat bagi kelangsungan bisnis perusahaan.

Alasan-alasan utama, mengapa penulis menggunakan kerangka kerja tersebut, adalah:

1. Seperti yang sudah disebutkan diatas mengenai kerangka kerjaTozer, bahwa model kerangka kerja tersebut memfokuskan diri terhadap strategi SI (Sistem Informasi) /TI (Teknologi Informasi), yang diharapkan dapat mendukung fungsi organisasi di Perusahaan sebagai supervisor(pengawas) yang memonitor kegiatan operasional kedua mitra swasta.

2. Menangkap gagasan, aspirasi dan ide strategis dari manajemen puncak dalam mengambil keputusan yang mengkomitmenkan diri atas pelaksanaan SI (Sistem Informas) / TI (Teknologi Informasi) di organisasi.

3. Memahami kebutuhan dasar organisasi sebagai core business (bisnis inti), dimana kegiatan bisnisnya bukan di bidang TI (Teknologi Informasi) dan diharapkan dengan dibuatnya perencanaan stratejik Sistem Informasi di Perusahaan, dapat memberikan solusi tepat yang akan ditawarkan oleh teknologi informasi.

\section{Metodologi Penelitian}

Adapun penjabaran mengenai langkah-langkah dari tahapan penelitian ini (lihat gambar 1) akan dijelaskan sebagai berikut:

\section{Lapisan Pertama, Penentuan Informasi Bisnis dan Dukungan Kebutuhan}

Tahap ini merupakan lapisan pertama dimana aktivitas kegiatan penelitian dimulai pertama kali dengan mengidentifikasi proses bisnis terkait dengan situasi dan kondisi sekarang ini, dan menganalisis pengaruh lingkungan eksternal perusahaan berdasarkan faktor-faktor tertentu, seperti: politik, ekonomi, sosial serta teknologi. Sedangkan metode analisa yang digunakan diantaranya adalah dengan melakukan wawancara secara open-ended ataupun dengan menggunakan probing question dengan beberapa pihak-pihak terkait di divisi Perusahaan tersebut, pengamatan dokumen-dokumen yang tersedia, observasi, analisis value chain, PEST (Politik, Ekonomi, Sosial, dan Teknologi), SWOT (Strengths, Weaknesses, Opportunities, and Threats) bisnis, serta analisis CSFs (Critical Success Factors) dimana disesuaikan dengan kebutuhan penelitian. Hasil dari tahapan ini berupa informasi-informasi yang dikumpulkan berdasarkan hasil wawancara, pemodelan strategi alternatif SWOT(Strengths, Weaknesses, Opportunities, and Threats) Perusahaan (Kekuatan dengan Peluang, Kelemahan dengan Peluang, Kekuatan dengan Hambatan, serta Kelemahan dengan Hambatan), dimana dari nantinya akan didapat dukungan kebutuhan dan informasi bisnis yang sejalan dengan kebutuhan bisnis perusahaan. Namun kegiatan tersebut pada intinya adalah untuk memahami bagaimana pola bisnis yang dijalankan oleh Perusahaan, sehingga hal ini bisa dijadikan acuan dalam menentukan strategi bisnis organisasi kedepannya. 
Lapisan Kedua, Pengkajian SI (Sistem Informasi) / TI (Teknologi Informasi) Berdasarkan Kondisi Saat Ini dan Identifikasi Pilihan Kebutuhan

Hasil kajian yang diperoleh dari analisis lingkungan bisnis pada lapisan pertama akan diproses dan dievaluasi dengan disesuaikanya pada kebutuhan organisasi. Aktifitas yang dilakukan pada tahap ini berupa:

1. Mengkaji ulang di setiap hasil dari analisa tersebut untuk ditentukan kebutuhan SI (Sistem Informasi) / TI (Teknologi Informasi) organisasi, yang nantinya akan dijadikan sebagai bahan rekomendasi dalam penetapan visi dan misi organisasi, mengidentifikasi dan memahami gagasan serta sasaran kebutuhan manajemen perusahaan akan sistem dan teknologi informasi, berdasarkan hasil wawancara dengan para pengguna ataupun manajer dan staf yang berkecimpung sehari-hari dalam bidang tersebut.

2. Melakukan pemetaan terhadap kebutuhan SI (Sistem Informasi) / TI (Teknologi Informasi), yang diidentifikasi berdasarkan kondisi sekarang ini (current) ke dalam portofolio aplikasi dari Mcfarlan, yang mana dikembangkan oleh Ward, Griffiths dan Whitemore (Tozer, 1996), dan penetapan kerangka arsitektur informasi yang terdiri dari sistem model bisnis perusahaan, pemetaan aplikasi, kerangka arsitektur data, serta mencari sumber-sumber informasi yang berkaitan dengan tren-tren teknologi informasi yang terjadi di masa kini dan yang akan datang dengan disesuaikan pada kebutuhan organisasi.

\section{Lapisan Ketiga - Penentuan Solusi Stratejik}

Proses aktivitas kegiatan yang dilakukan pada tahap ketiga dalam menentukan solusi stratejik SI (Sistem Informasi) / TI (Teknologi Informasi)Perusahaan, diantaranya berupa:

1. Penetapan visi dan misi stratejik SI (Sistem Informasi) / TI (Teknologi Informasi). Perusahaan, mengkaji dan mengidentifikasi kekuatan, kelemahan, peluang, serta hambatan pada sistem dan teknologi yang diterapkan di perusahaan ini dengan menggunakan analisis SWOT (Strengths, Weaknesses, Opportunities, and Threats), dimana kemudian didapat model strategi alternatif yang tepat dari hasil analsis tersebut.

2. Pada tahapan ini juga akan disinggung mengenai usulan mengenai alur proses pengiriman data dari Mitra Swasta ke Perusahaan serta usulan Sistem Informasi baru yang didapat setelah dilakukan analisis sebelumnya atas permasalahan kebutuhan yang dihadapi organisasi saat ini..

3. Mengkaji dukungan kebutuhan SI (Sistem Informasi) / TI (Teknologi Informasi) dan dukungan infrastruktur atas dasar hasil analisis SWOT(Strengths, Weaknesses, Opportunities, and Threats) dan CSFs (Critical Success Factors), dan terakhir akan dimuat usulan rancangan arsitektur TI (Teknologi Informasi) untuk masa depan berdasarkan hasil evaluasi terhadap skema arsitektur jaringan LAN(Local Area Network) dan WAN(Wide Area Network) yang dimiliki Perusahaan sebelumnya.

\section{Lapisan Keempat - Persiapan dan Perencanaan Implementasi}

Pada lapisan keempat di tahapan terakhir ini aktifitas kegiatan yang dilakukan adalah menetapkan time frame atas pelaksanaan proyek-proyek SI (Sistem Informasi) / TI (Teknologi Informasi) dari hasil kajian analisis sebelumnya, yang kemudian dituangkan kedalam diagram Gant Charts, sehingga dapat menampilkan prioritas utama dari kebutuhan sistem dan teknologi informasi yang paling tepat untuk diterapkan di Perusahaan. 


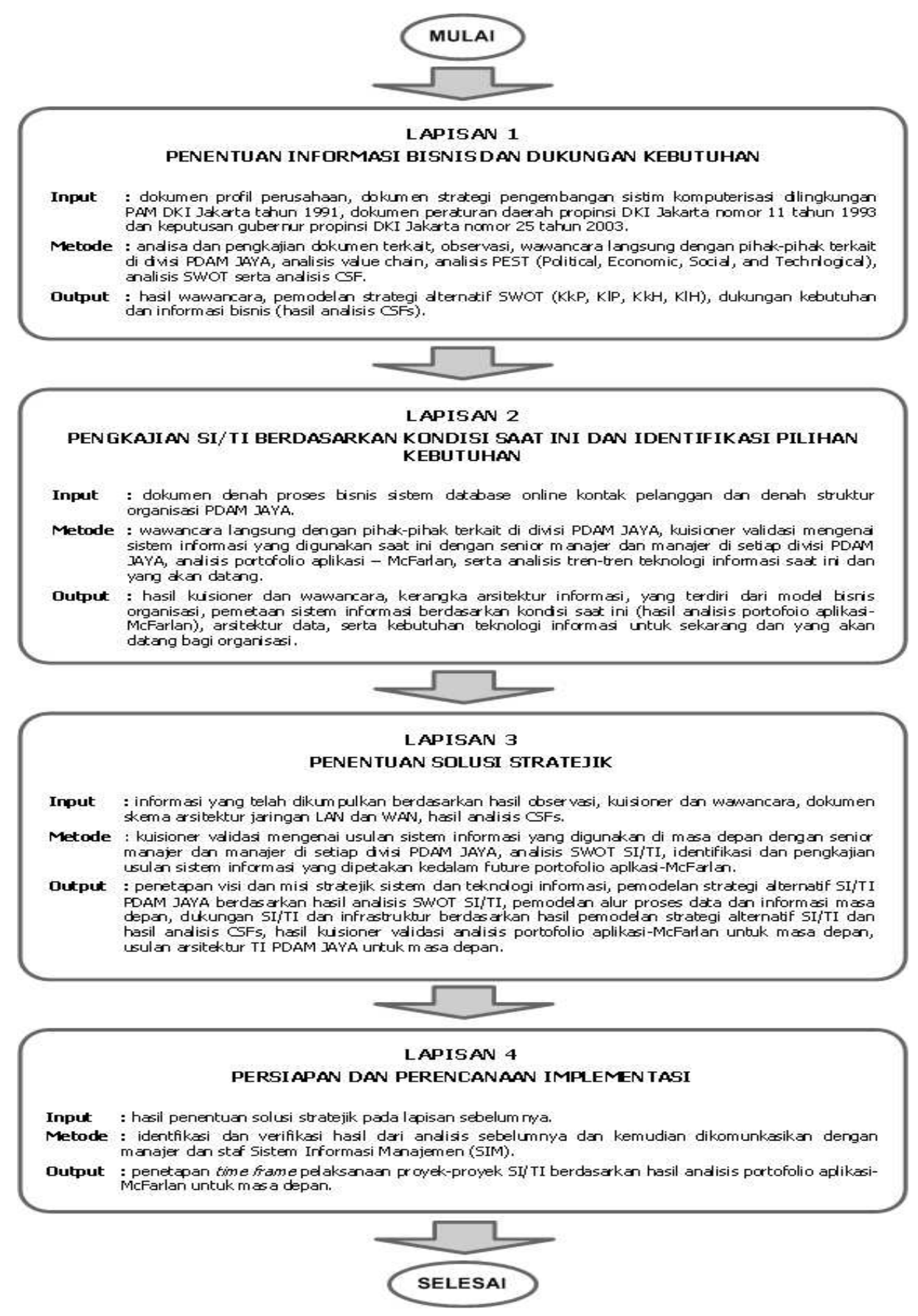

Gambar 1. Diagram Alir dari Metode Strategic Planning for IS/IT yang telah dimodifikasi (Tozer, 1996)

\section{Hasil dan Pembahasan}

\section{Penentuan Informasi Bisnis dan Dukungan Kebutuhan}

Lapisan pertama dalam penyusunan perencanaan stratejik Sistem Informasi disini memuat beberapa analisa yang dilakukan, dimana diantaranya adalah:

\section{Analisis Value Chain}

Aktivitas primer pada Perusahaan bermula dari penyerahan laporan rekapitulasi pelanggan oleh pihak Mitra Swasta. Setiap laporan yang masuk, dikonversi terlebih dahulu sesuai 
dengan format yang dibutuhkan oleh perusahaan. Kemudian dikirim hasil konversi tersebut kedalam database ataupun di print-out secara langsung untuk siap disajikan ke tiap-tiap divisi yang memerlukannya. Data pelaporan seperti: master cetak dan master bayar, nantinya akan dilakukan proses rekonsiliasi untuk mengetahui apakah rekening yang tercetak ke pelanggan sesuai dengan jumlah rekening yang dibayarkan. Dalam proses rekonsiliasi, terdapat dua divisi yang menanganinya. Divisi Teknik dan Pelayanan melakukan rekonsiliasi atas dasar kubikasi atas tagihan yang terbayarkan oleh pelanggan, sedangkan pada divisi akuntansi dan keuangan melakukan rekonsiliasi yang berkaitan dengan pemasukkan dan pengeluaran uang di bank bersama.

Setelah data-data pelaporan yang diserahkan oleh Mitra Swasta tersebut selesai diproses, kemudian pada tahap berikutnya adalah tahapan dimana dikeluarkan berita acara atas penarikan dana rekening bersama pada bank yang telah ditunjuk sebagai proses persetujuan bahwa pihak Mitra Swasta berhak mendapatkan hak sesuai dengan hasil rekonsiliasi tersebut. Sedangkan untuk hasil pemrosesan data kinerja teknis nantinya akan dihasilkan laporan pemantauan dan evaluasi kinerja Mitra Swasta pada bulan lalu. Adapun laporan lainnya yang dihasilkan dari proses validasi dan evaluasi sebelumnya adalah laporan hasil pemantauan dan evaluasi investasi dan laporan keuangan yang terdapat pada Mitra Swasta.

Dengan demikian setelah dikaji lebih lanjut laporan tersebut, jika terdapat pelanggaran bahwa pihak Mitra Swasta dalam beberapa hari atau beberapa minggu tidak segera mengatasi masalah gangguan yang terjadi pada pelanggan di area tertentu atau dalam proses rekonsiliasi, perhitungan yang didapat tidak sesuai dengan jumlah target yang ditentukan secara bersama. Maka pihak Mitra Swasta akan diberikan pemberitahuan teguran pertama sampai dengan teguran ketiga sesuai dengan konsekuensi yang diterima serta dilakukan melalui konfirmasi lebih lanjut kepada pihak Mitra Swasta untuk melakukan rekonsilisasi ulang sampai target yang dicapai terpenuhi. Sedangkan untuk aktivitas pendukung yang terjadi di Perusahaan, ada beberapa susunan kegiatan yang dilakukan, diantaranya adalah: aktivitas pendukung yang berhubungan dengan infrastruktur perusahaan, pengelolaan sumber daya manusia, pengembangan teknologi dan pengadaan barang teknologi informasi. Berikut adalah ilustrasi aktivitas kegiatan bisnis Perusahaan yang ditunjukkan pada Gambar 2.

\section{Analisis CSFs (Critical Success Factors)}

Menetapkan rencana perusahaan untuk lima sampai dengan sepuluh tahun kedepan, diperlukan ada kata kesepakatan dan keputusan yang kuat dari manajemen puncak. Karena memang hal ini berkaitan langsung dengan kinerja perusahaan selama ini. Jika jadi dilakukan implementasi sistem dan teknologi informasi untuk mendukung sekaligus menunjang bisnis perusahaan, maka harus diiringi dengan perhitungan yang tepat. Bagaimana dan kapan mereka perlu menetapkan proyek-proyek SI (Sistem Informasi) / TI (Teknologi Informasi), serta apakah pengelolaannya sudah sesuai. Semua itu sudah menjadi peraturan atau tata aturan yang wajib dipatuhi dan di realisasikan baik oleh perusahaan daerah, departemen, lembaga instansi dan badan-badan usaha milik negara, dimana sesuai dengan Kepres (Keputusan Presiden) tahun 80, yang mana mengatur perundang-undangan mengenai pengadaan barang dan jasa.

Adapun kajian analisis CSFs (Critical Success Factors)yang dilakukan terhadap Perusahaan, dapat dijelaskan pada Tabel 1. 


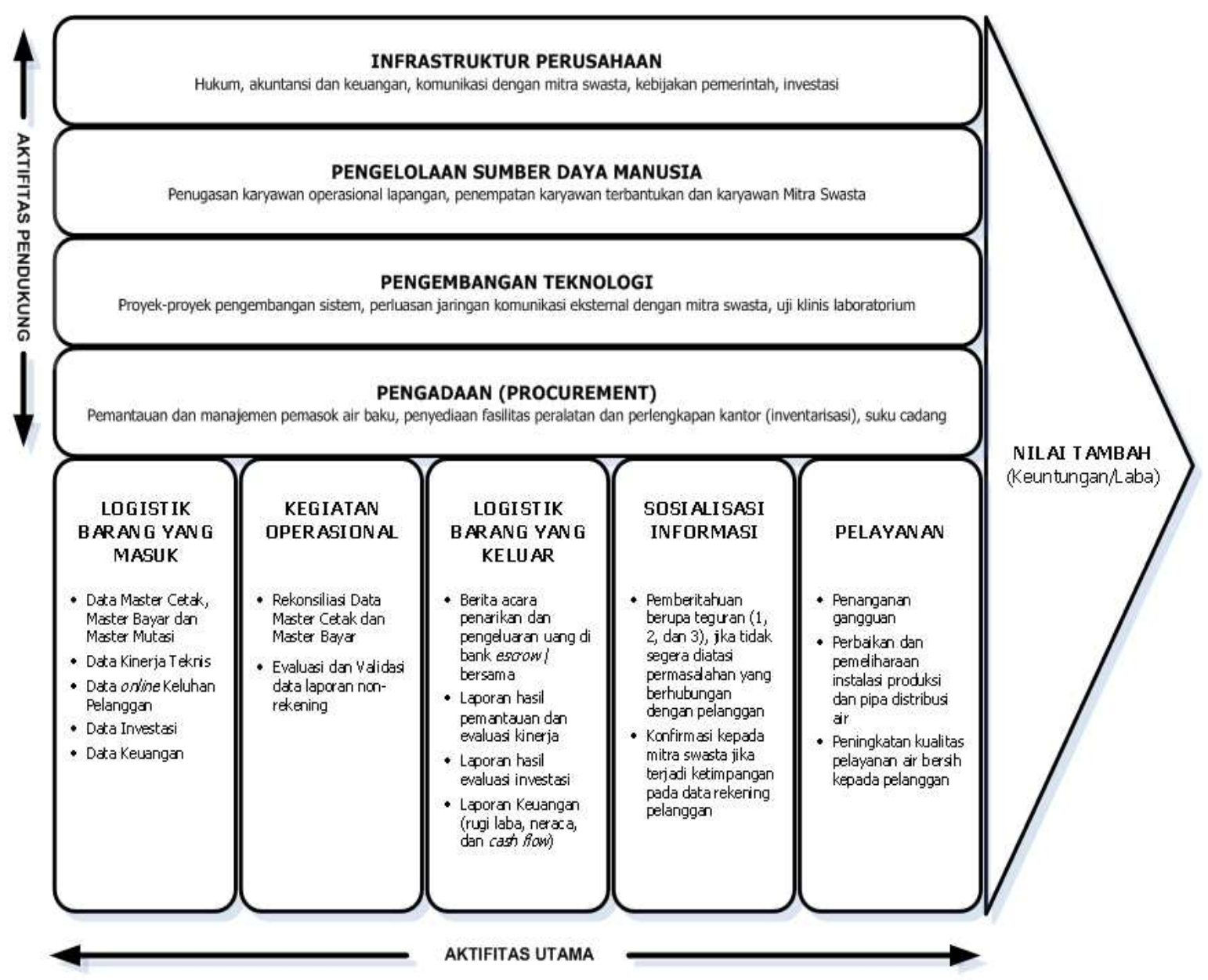

Gambar 2. Modifikasi Analisis Rantai Nilai (Value Chain) Perusahaan

\begin{abstract}
Pengkajian SI (Sistem Informasi) / TI (Teknologi Informasi) Berdasarkan Kondisi Saat Ini dan Identifikasi Pilihan Kebutuhan

Pada tahap kedua dari penyusunan perencanaan strategis Sistem Informasi, adalah mengkaji sistem dan teknologi informasi berdasarkan kondisi saat ini dan mengidentifikasi beberapa pilihan kebutuhan untuk menetapkan arsitektur informasi yang tepat bagi organisasi. Hal yang perlu dilakukan pertama kali adalah menggambarkan kondisi lingkungan SI (Sistem Informasi) / TI (Teknologi Informasi) di dalam dan di luar organisasi, diantaranya melingkupi: pemetaan sistem aplikasi, arsitektur data, serta model bisnis, yang mana merupakan bagian dari arsitektur informasi.
\end{abstract}


Tabel 1. Analisis CSFs (Critical Success Factors) Perusahaan

\begin{tabular}{|c|c|c|c|c|}
\hline No. & TUJUAN/SASARAN & $\begin{array}{l}\text { C.S.Fs. (Critical } \\
\text { Success Factors) }\end{array}$ & $\begin{array}{l}\text { PENGUKURAN } \\
\text { KINERJA }\end{array}$ & $\begin{array}{l}\text { DUKUNGAN KEBUTUHAN DAN } \\
\text { INFORMASI BISNIS }\end{array}$ \\
\hline 1. & $\begin{array}{l}\text { Efisiensi dan efektifitas } \\
\text { sumber daya manusia, } \\
\text { khususnya yang } \\
\text { berkaitan dengan } \\
\text { teknologi informasi }\end{array}$ & $\begin{array}{l}\text { Pemenuhan } \\
\text { ketersediaan tenaga } \\
\text { ahli/orang-orang yang } \\
\text { tepat dan kompeten } \\
\text { dalam bidang TI } \\
\text { (Teknologi Informasi) }\end{array}$ & $\begin{array}{l}\text { Tingkat keahlian dan } \\
\text { pengalaman dari } \\
\text { sumber daya manusia } \\
\text { yang dimiliki }\end{array}$ & $\begin{array}{l}\text { Mengadakan outsource untuk tenaga ahli } \\
\text { tambahan yang memiliki latar belakang } \\
\text { khususnya di bidang TI (Teknologi } \\
\text { Informasi) serta memiliki keahlian dan } \\
\text { pengalaman yang sesuai dengan kriteri } \\
\text { dan ketentuan yang telah di tetapkan } \\
\text { oleh Perusahaan }\end{array}$ \\
\hline 2. & $\begin{array}{l}\text { Kemudahan dan } \\
\text { keakuratan dalam } \\
\text { penyajian laporan } \\
\text { sehari-hari }\end{array}$ & $\begin{array}{l}\text { Kehandalan dan } \\
\text { ketersediaan sistem } \\
\text { komputerisasi dalam } \\
\text { menangani data dan } \\
\text { informasi perusahaan }\end{array}$ & $\begin{array}{l}\text { Tingkat kehandalan, } \\
\text { kemudahan, } \\
\text { keakuratan dan } \\
\text { akuntabilitas data } \\
\text { laporan yang disajikan }\end{array}$ & $\begin{array}{l}\text { Perlunya dukungan Sistem Informasi yang } \\
\text { terintegrasi antar divisi secara } \\
\text { keseluruhan, sehingga memberikan } \\
\text { kemudahan dalam mengakses data } \\
\text { pelaporan yang disajikan }\end{array}$ \\
\hline 3. & $\begin{array}{l}\text { Peningkatan peranan, } \\
\text { fungsi divisi SIM } \\
\text { (Sistem Informasi } \\
\text { Manajemen) dalam } \\
\text { menunjang kegiatan } \\
\text { bisnis perusahaan }\end{array}$ & $\begin{array}{l}\text { Prosedur, fungsi dan } \\
\text { peranan pimpinan } \\
\text { dan staf divisi Sistem } \\
\text { Informasi Manajemen } \\
\text { (SIM) }\end{array}$ & $\begin{array}{l}\text { Tingkat pelayanan } \\
\text { dan keaktifan } \\
\text { kegiatan operasional } \\
\text { TI (Teknologi } \\
\text { Informasi) di dalam } \\
\text { perusahaan }\end{array}$ & $\begin{array}{l}\text { - Peningkatan standar keahlian dan } \\
\text { kemampuan karyawan/staf } \\
\text { - Peningkatan efektifitas dan } \\
\text { produktifitas karyawan/staf untuk } \\
\text { mendukung bisnis perusahaan } \\
\text { - Memberlakukan SLA (Service Level } \\
\text { Agreement) }\end{array}$ \\
\hline 4. & $\begin{array}{l}\text { Pengadaan proyek- } \\
\text { proyek } \\
\text { Teknologi/Sistem } \\
\text { Informasi untuk } \\
\text { mendukung kinerja } \\
\text { perusahaan }\end{array}$ & $\begin{array}{l}\text { Kemampuan } \\
\text { manajemen dalam } \\
\text { mengambil } \\
\text { keputusan, khususnya } \\
\text { yang berkaitan } \\
\text { dengan sistem dan } \\
\text { teknologi informasi }\end{array}$ & $\begin{array}{l}\text { Dukungan prioritas } \\
\text { dari seluruh pihak } \\
\text { manajemen terkait }\end{array}$ & $\begin{array}{l}\text { Mengupayakan adanya dukungan dari } \\
\text { manajemen dan pihak-pihak terkait } \\
\text { lainnya untuk mewujudkan terealisasi } \\
\text { proyek Sistem Informasi tersebut } \\
\text { - Melakukan pemberdayaan Sistem } \\
\text { Informasi yang sudah ada dan } \\
\text { mengadakan penambahan perangkat } \\
\text { lunak, perangkat keras dan } \\
\text { infrastruktur lainnya yang dapat } \\
\text { mendukung Sistem Informasi baru } \\
\text { - Melakukan perekrutan jasa konsultan } \\
\text { dalam merencanakan proyek-proyek } \\
\text { Teknologi/Sistem Informasi } \\
\text { - Mengadakan pelatihan atau workshop }\end{array}$ \\
\hline 5. & $\begin{array}{l}\text { Optimalisasi } \\
\text { penerimaan hasil } \\
\text { rekonsiliasi data } \\
\text { master cetak dan } \\
\text { bayar }\end{array}$ & $\begin{array}{l}\text { Kemudahan } \\
\text { pengaksesan dan } \\
\text { keakuratan informasi } \\
\text { rekapitulasi data } \\
\text { rekening master } \\
\text { cetak/bayar yang } \\
\text { diberikan oleh pihak } \\
\text { mitra swasta }\end{array}$ & $\begin{array}{l}\text { Tingkat keabsahan, } \\
\text { keterbukaan dan } \\
\text { keakuratan data dan } \\
\text { informasi yang } \\
\text { disajikan oleh mitra } \\
\text { swasta }\end{array}$ & $\begin{array}{l}\text { - Merencanakan jaringan sistem online } \\
24 \text { jam, yang terhubung ke pihak mitra } \\
\text { swasta } \\
\text { - Melakukan standardisasi format } \\
\text { pelaporan yang disajikan oleh pihak } \\
\text { Mitra Swasta } \\
\text { - Melakukan pencatatan secara bersama } \\
\text { di lapangan }\end{array}$ \\
\hline 6. & $\begin{array}{l}\text { Meningkatkan mutu } \\
\text { dan kualitas pelayanan } \\
\text { terhadap pelanggan }\end{array}$ & $\begin{array}{l}\text { Kemampuan mitra } \\
\text { swasta dalam } \\
\text { menanggapi dan } \\
\text { menangani masalah } \\
\text { pelanggan }\end{array}$ & $\begin{array}{l}\text { Jumlah keluhan } \\
\text { pelanggan yang telah } \\
\text { ditangani oleh mitra } \\
\text { swasta }\end{array}$ & $\begin{array}{l}\text { Melakukan uji sampling dari beberapa } \\
\text { pelanggan yang mengeluh agar dapat } \\
\text { diukur tingkat keakuratan data laporan } \\
\text { keluhan pelanggan yang di sajikan oleh } \\
\text { mitra swasta secara online }\end{array}$ \\
\hline
\end{tabular}

\section{Pemetaan Sistem Informasi}

Secara umum, aplikasi yang sering digunakan di perusahaan ini tidak sedikit di kembangkan secara in-house, maupun ada sebagian aplikasi yang di bangun secara outsourcemelalui lelang terbuka. Dalam penggunaannya, hanya beberapa aplikasi yang benar-benar di manfaatkan secara maksimal. Karena, sedikit sekali sumber daya manusia yang paham akan pemakaiannya. Walaupun, sudah ada pelatihan, baik di dalam maupun di luar perusahaan yang menekankan pentingnya penerapan sistem dan teknologi informasi untuk mendukung fungsi dan peranan organisasi saat ini. Pada kenyataannya hanya beberapa aplikasi yang digunakan di perusahaan ini (lihat Tabel 2). 
Tabel 2. Matriks Portofolio Aplikasi Perusahaan Berdasarkan Kondisi Sekarang

\begin{tabular}{|c|c|c|c|c|c|c|c|c|c|}
\hline \multirow{2}{*}{ STRATEGIC } & \multirow{2}{*}{ KET } & \multicolumn{3}{|c|}{ Kriteria } & \multirow{2}{*}{$\begin{array}{l}\text { HIGH POTENSIAL } \\
\text { - "Turnaround" }\end{array}$} & \multirow{2}{*}{ KET } & \multicolumn{3}{|c|}{ Kriteria } \\
\hline & & $\mathbf{s}$ & TS & TM & & & $\mathbf{s}$ & TS & TM \\
\hline $\begin{array}{l}\text { SiLab (Sistem } \\
\text { Informasi } \\
\text { Laboratorium) }\end{array}$ & $\begin{array}{l}\text { Ada dan dalam } \\
\text { proses } \\
\text { pengembangan }\end{array}$ & 0,588 & & 0,412 & & & & & \\
\hline \multirow{2}{*}{ KEY OPERATIONAL } & \multirow{2}{*}{ KET } & \multicolumn{3}{|c|}{ Kriteria } & \multirow{2}{*}{ SUPPORT } & \multirow{2}{*}{ KET } & \multicolumn{3}{|c|}{ Kriteria } \\
\hline & & $\mathbf{s}$ & TS & TM & & & $\mathbf{s}$ & TS & TM \\
\hline $\begin{array}{l}\text { SiRekon MC dan MB } \\
\text { (Sistem Informasi } \\
\text { Rekonsiliasi Master } \\
\text { Cetak dan Bayar) }\end{array}$ & Ada & 0,588 & & 0,412 & $\begin{array}{l}\text { SiLKBD (Sistem } \\
\text { Informasi Lembar } \\
\text { Kendali Berkas \& } \\
\text { Disposisi) }\end{array}$ & Ada & 1,000 & & \\
\hline $\begin{array}{c}\text { SiKeu (Sistem } \\
\text { Infomasi Keuangan) }\end{array}$ & Ada & 0,588 & & 0,412 & $\begin{array}{c}\text { Aplikasi } \\
\text { Perkantoran }\end{array}$ & Ada & 0,941 & & 0,058 \\
\hline $\begin{array}{l}\text { Silugan (Sistem } \\
\text { Informasi Keluhan } \\
\text { Pelanggan }\end{array}$ & Ada & 0,588 & & 0,412 & Aplikasi Internet & Ada & 1,000 & & \\
\hline
\end{tabular}

Tabel 3. Matriks Portofolio Aplikasi Masa Depan PERUSAHAAN

\begin{tabular}{|c|c|c|c|c|c|c|c|c|c|}
\hline \multirow{2}{*}{ STRATEGIC } & \multirow{2}{*}{ KET } & \multicolumn{3}{|c|}{ Kriteria } & \multirow{2}{*}{$\begin{array}{c}\text { HP - } \\
\text { "Turnaround" }\end{array}$} & \multirow[t]{2}{*}{ KET } & \multicolumn{3}{|c|}{ Kriteria } \\
\hline & & $\mathbf{S}$ & TS & TM & & & $\mathbf{S}$ & TS & TM \\
\hline \multirow[t]{2}{*}{$\begin{array}{c}\text { SiOGIS (Sistem } \\
\text { Informasi Online } \\
\text { Geographic } \\
\text { Information System) }\end{array}$} & $\begin{array}{c}\text { Usulan } \\
\text { Pengembangan }\end{array}$ & 0,588 & 0 & 0,412 & $\begin{array}{l}\text { SiLuKTek (Sistem } \\
\text { Informasi Evaluasi } \\
\text { Kinerja Teknis) }\end{array}$ & $\begin{array}{l}\text { Usulan } \\
\text { /Baru }\end{array}$ & 1,000 & 0 & 0 \\
\hline & & & & & $\begin{array}{l}\text { SiPeg (Sistem } \\
\text { Informasi } \\
\text { Kepegawaian) }\end{array}$ & $\begin{array}{l}\text { Usulan } \\
\text { /Baru }\end{array}$ & 0,882 & 0 & 0,118 \\
\hline \multirow{2}{*}{ KEY OPERATIONAL } & \multirow{2}{*}{ KET } & \multicolumn{3}{|c|}{ Kriteria } & \multirow{2}{*}{ SUPPORT } & KET & \multicolumn{3}{|c|}{ Kriteria } \\
\hline & & $\mathbf{S}$ & TS & TM & & & $\mathbf{S}$ & TS & TM \\
\hline $\begin{array}{c}\text { SiRekon MC dan MB } \\
\text { (Sistem Informasi } \\
\text { Rekonsiliasi Master } \\
\text { Cetak dan Bayar) }\end{array}$ & Ada & 0,588 & 0 & 0,412 & $\begin{array}{l}\text { SiLKBD (Sistem } \\
\text { Informasi Lembar } \\
\text { Kendali Berkas \& } \\
\text { Disposisi) }\end{array}$ & Ada & 0,941 & 0 & 0,058 \\
\hline $\begin{array}{c}\text { SiKeu (Sistem } \\
\text { Infomasi Keuangan) }\end{array}$ & Ada & 0,588 & 0 & 0,412 & $\begin{array}{c}\text { Aplikasi } \\
\text { Perkantoran }\end{array}$ & Ada & 0,941 & 0 & 0,058 \\
\hline $\begin{array}{c}\text { Silugan (Sistem } \\
\text { Informasi Keluhan } \\
\text { Pelanggan }\end{array}$ & Ada & 0,588 & 0 & 0,412 & Aplikasi Internet & Ada & 1,000 & 0 & 0 \\
\hline $\begin{array}{l}\text { SiLab (Sistem } \\
\text { Informasi } \\
\text { Laboratorium) }\end{array}$ & $\begin{array}{l}\text { Ada dan dalam } \\
\text { proses } \\
\text { pengembangan }\end{array}$ & 0,588 & 0 & 0,412 & $\begin{array}{l}\text { SiJandu (Sistem } \\
\text { Jaringan Online } \\
\text { Terpadu) }\end{array}$ & $\begin{array}{l}\text { Usulan } \\
\text { /Baru }\end{array}$ & 1,000 & 0 & 0 \\
\hline $\begin{array}{c}\text { SiEvi (Sistem } \\
\text { Informasi Evaluasi } \\
\text { Investasi) }\end{array}$ & Usulan/Baru & 0,588 & 0 & 0,412 & $\begin{array}{c}\text { SiPRP (Sistem } \\
\text { Informasi Pajak } \\
\text { Rekening } \\
\text { Pelanggan) }\end{array}$ & $\begin{array}{l}\text { Usulan } \\
\text { /Baru }\end{array}$ & 0,823 & 0,176 & 0 \\
\hline $\begin{array}{l}\text { SiKoDat (Sistem } \\
\text { Informasi Konversi } \\
\text { Data Terpusat) }\end{array}$ & Usulan/Baru & 0,529 & 0,058 & 0,412 & & & & & \\
\hline
\end{tabular}




\section{Penentuan Solusi Stratejik}

Pada tahap ketiga, merupakan tahap penentuan strategi Sistem Informasi Perusahaan dalam memposisikan peran dan pemanfaatannya sehingga diharapkan dapat mengoptimalkan kinerja perusahaan dan meningkatkan produktifitas karyawan.

\section{Portofolio Aplikasi Masa Depan Perusahaan}

Berdasarkan hasil analisa yang dilakukan dengan mempertimbangkan aspek-aspek pada bisnis perusahaan, maka dapat ditarik kesimpulan bahwa dalam pengembangan Sistem Informasi untuk periode jangka panjang harus memperhatikan prioritas dukungan yang nantinya akan digunakan.

Sistem Informasi yang dikembangkan nantinya akan disesuaikan dengan kebutuhan perusahaan, dimana dalam mengembangkan Sistem Informasi yang baik, diantaranya:

1. Harus berkesinambungan dengan tujuan dari rencana stratejik perusahaan.

2. Mempergunakan aplikasi open source, sebagai dukungan terhadap Pemerintah dalam mensukseskan IGOS (Indonesia Go Open Source).

3. Digunakan sebagai basis dasar kekuatan Perusahaan dalam meningkatkan kinerja operasional perusahaan (lihat Tabel 3).

\section{Persiapan dan Perencanaan Implementasi}

Dalam merumuskan perencanaan strategis Sistem Informasi diperlukan komitmen yang begitu besar, baik itu dari pihak manajemen perusahaan maupun pihak pelaksana proyek yang mana nantinya bisa terealisasi dengan baik penerapan TI (Teknologi Informasi) di Perusahaan. Berdasarkan hasil analisa sebelumnya mengenai kebutuhan bisnis pada Perusahaan, maka dapat diidentifikasi time frame yang tepat dalam menjadwalkan pelaksanaan proyek tersebut. Tahapan-tahapan waktu pelaksanaan yang dirumuskan oleh penulis dapat terlihat Gambar 3 berikut ini.

\begin{tabular}{|c|c|c|c|c|c|c|c|}
\hline \multirow{2}{*}{ ID } & \multirow{2}{*}{ Prioritas Pelaksanaan Proyek } & \multirow{2}{*}{ Start } & \multirow{2}{*}{ Finish } & \multirow{2}{*}{ Duration } & 2009 & 2010 & 2011 \\
\hline & & & & & 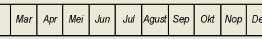 & 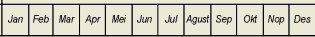 & 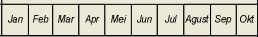 \\
\hline 1 & $\begin{array}{l}\text { Pembangunan Infrastruktur } \\
\text { Jaringan Internal dan Pengadaan } \\
\text { Perangkat Komputer Baru }\end{array}$ & 01/04/2009 & 29/06/2009 & $12 \mathrm{w} 4 \mathrm{~d}$ & & & \\
\hline 2 & $\begin{array}{l}\text { SiJandu (Sistem Informasi } \\
\text { Jaringan Online Terpadu) }\end{array}$ & $01 / 05 / 2009$ & $31 / 08 / 2009$ & $17 w 2 d$ & & & \\
\hline 3 & $\begin{array}{l}\text { SiKodat (Sistem Informasi } \\
\text { Konversi Data Terpusat) }\end{array}$ & 01/09/2009 & $30 / 11 / 2009$ & $13 w$ & & & \\
\hline 4 & $\begin{array}{l}\text { SiEvi (Sistem Informasi Evaluasi } \\
\text { Investasi) dan SiKeu (Sistem } \\
\text { Informasi Keuangan) }\end{array}$ & 01/01/2010 & $31 / 03 / 2010$ & $12 \mathrm{w} 4 \mathrm{~d}$ & & & \\
\hline 5 & $\begin{array}{l}\text { SiPRP (Sistem Informasi Pajak } \\
\text { Rekening Pelanggan) }\end{array}$ & $01 / 04 / 2010$ & $30 / 09 / 2010$ & $26 \mathrm{w} 1 \mathrm{~d}$ & & & \\
\hline 6 & $\begin{array}{l}\text { SiPeg (Sistem Informasi } \\
\text { Kepegawaian) }\end{array}$ & $01 / 10 / 2010$ & $31 / 03 / 2011$ & $26 w$ & & & \\
\hline 7 & $\begin{array}{l}\text { SiOGIS (Sistem Informasi Online } \\
\text { Geographic Information System) }\end{array}$ & 01/04/2011 & $30 / 09 / 2011$ & 26w 1d & & & \\
\hline
\end{tabular}

Gambar 3. Time Frame Perencanaan SI / TI 


\section{Simpulan dan Saran}

\section{Simpulan}

Dari hasil penelitian yang dilakukan di sebuah badan usaha milik daerah, maka untuk dapat menjawab pertanyaan penelitian ini, dapat diambil kesimpulan bahwa:

1. Sistem Informasi yang digunakan Perusahaan saat ini tidak dapat mengatasi masalah yang terjadi di internal perusahaan, sehingga aplikasi yang terdapat di tiap-tiap divisi tidak terintegrasi satu sama lain.

2.Portofolio aplikasi, menitik beratkan pada efektifitas dan efisiensi dalam pendistribusian data-data yang berkaitan dengan laporan kegiatan operasional Mitra Swasta sehari-hari, serta mengedepankan nilai-nilai pendayagunaan Sistem Informasi itu sendiri.

3.Rumusan strategi Teknologi/Sistem Informasi Perusahaan menekankan pada kebutuhan akan standardisasi penerapan teknologi informasi, membangun infrastruktur jaringan komunikasi baik internal maupun ekternal yang dapat menghubungkan dengan pihak Mitra Swasta, dan membuka kesempatan kepada karyawan dan staf untuk dapat menambah wawasan dan pengetahuan akan sistem dan teknologi informasi yang tepat guna melalui pelatihan-pelatihan yang di adakan secara inhouseataupun outdoor.

4.Dukungan komponen teknis pendukung baik dari teknologi basis data hingga infrastruktur TI (Teknologi Informasi) yang digunakan, semua harus mengacu kepada kebutuhan dasar dari bisnis inti Perusahaan.

5.Time frame perencanaan strategis Sistem Informasi Perusahaan memprioritaskan pada pembangunan dan pengembangan sistem dan teknologi yang dilakukan secara berkala.

\section{Saran}

Dengan demikian, setelah diungkapkan hasil dari kesimpulan di atas maka saran penulis bahwa:

1.Untuk meningkatkan kinerja perusahaan agar lebih optimal, maka diperlukan adanya pelatihan-pelatihan, baik itu dilakukan secara tatap muka maupun dilakukan pembelajaran secara elektronik melalui jarak jauh (distance learning).

2.Dalam meningkatkan efektifitas dan efesiensi pekerjaan sehari-hari yang dilakukan oleh Perusahaan, maka diperlukan sistem dan teknologi informasi tepat guna, yaitu dengan menerapkan networkonline system (sistem jaringan online) di setiap penyajian laporan data-data pelanggan baik berupa rekening maupun non-rekening, sehingga dalam membuktikan bahwa data-data yang diterima oleh Perusahaan dari Mitra Swasta merupakan data yang valid dan akurat.

3. Menata kembali arsitetur infrastruktur teknologi informasi dengan mengalokasikan sumber daya yang ada untuk bisa dioptimalkan pendayagunaanya, menambah sejumlah perangkat komputer server baru dan perangkat pendukung lainnya untuk dapat mengantisipasi peningkatan kapasitas pengelolaan data-data online Mitra Swasta serta memisahkan antara jaringan internal dan eksternal perusahaan, sehingga dalam jalur komunikasi data yang masuk dan keluar Perusahaan dapat dimonitoring secara baik.

\section{Daftar Pustaka}

Barus, S.P. (2000). Perencanaan Strategis untuk Sistem Informasi : Studi Kasus PT. Krakatau Engineering Corporation. Jakarta: Pasca Sarjana MTI UI, Fasilkom-UIMTI.

Boynton, A. C., \& Zmud, R. W. (1987). Information Technology Planning in the 1990's: Directions for Practice and Research. MIS Quarterly, Vol. 11, No. 1, pp. 59-71, Available at: http://jstor.org. 
Brumec, J., \& Vrcek, N. (2002). Strategic Planning of Information Systems - A Survey of Methodology - Information Technology Interfaces. Proceedings of the 24th International Conference, University of Zagreb, pp.246, Available at: http://cit.zesoi.fer.hr/downloadPaper.php?paper=391.

Lederer, L. A.,\& Sethi, V. (1988). The Implementation of Strategic Information Systems Planning Methodologies. MIS Quarterly, Vol. 12 No.3, pp. 445-461, Available at: http://proquest.umi.com.

Tozer, E. E. (1996). Strategy IS/IT Planning. Washington, USA : Butterworth-Heinemann.

Ward, J., \&Peppard, J. (2002). Strategic Planning For Information System ( ${ }^{\text {rd }}$ ed.). England: John Willey \& Sons, LTD. 